\title{
Un ejercicio de lectura \\ (De cómo Azorín se inventa a la mujer al leer el Quijote)
}

\section{JUAN CARLOS RODRÍGUEZ}

Universidad de Granada

España

1) Creo que fue Azorín el primero que leyó el Quijote en clave de mujeres. Y además de una manera fascinante (quiero decir, que pretendía hipnotizarnos). Pues dejando al margen todas las elucubraciones más o menos románticas y francamente espúreas o risibles que se habían acumulado en torno a Dulcinea, Azorín va directamente al grano, a lo concreto, a aquello que Ortega definió -con su habitual brizna de cursilería- como "los primores de lo vulgar". Esto es, de lo cotidiano. Azorín ya había publicado en 1905 La ruta de don Quijote, un libro donde Azorín señalaba hasta qué punto Cervantes condena -él lo dice- a Don Quijote no en estricto por su "idealismo" sino por la exaltación loca de tal idealismo que se habría convertido, según Azorín, en un modelo inútil para España. Podríamos añadir en este sentido que en realidad Azorín se sitúa entre la Vida de Don Quijote y Sancho (1905) y El sepulcro de Don Quijote (1906) de Unamuno y las Meditaciones del Quijote (1914) de Ortega, para darnos su propia versión del asunto.

De hecho, toda la crítica en torno a Cervantes y el Quijote ha estado prisionera de aquel centenario de 1905 (prolongado hasta 1915) ${ }^{1}$. Un horizonte que no debería tener nada que ver con el nuestro del año 2010. Y sin embargo me temo que los planteamientos de entonces se hayan mantenido inmutables (Don Quijote representaría

\footnotetext{
${ }^{1}$ Vid. sobre todo esto JCR (2003). El escritor que compró su propio libro para leer el Quijote, Barcelona: Debate.
} 
lo trascendental y Sancho lo empírico o lo mundano, según quedó establecido desde Schelling y los románticos) y lo único que parece haber variado es la introducción de temas nuevos de estudio, temas como éste del Quijote en clave de mujeres. Pero, insisto, quizás no se haya cambiado en exceso la problemática de fondo. Si Unamuno consideraba a Cervantes como un mal evangelista (y por eso reescribe la vida supuestamente auténtica de los dos protagonistas) lo hace de acuerdo con lo que se ha llamado su "optimismo trágico", lo que Ortega consideraría un irracionalismo vital al que él opondría los matices de su propia razón vital. Claro que para que el argumento de Unamuno funcionase, en esa Vida tuvo que utilizar un procedimiento semejante al que utilizó Dostoyevski en El idiota, en la versión definitiva del príncipe Myshkin (hay muchas versiones previas del libro ruso), esto es, convertir a Don Quijote en una especie de santo o místico laico. Con lo cual resulta que no sería propiamente Don Quijote sino en realidad Alonso Quijano, el Bueno, el verdadero protagonista, en la sombra, del texto cervantino. Es decir, el signo de que -como en la Encarnación de Cristo o en la dialéctica hegeliana, que es su copia laica- el en sí y el para sí del hidalgo no se separan nunca (pese a su extrañamiento equívoco, sus desvíos de locuras caballerescas). Y por ello la verdad de tal no-separación entre el en sí y el para sí del espíritu sólo se nos revelaría en la muerte del personaje, una muerte en la que el caballero desaparecería y surgiría plena la autoconciencia iluminadora del hidalgo. Quizá por ello, muy poco tiempo después, el propio Unamuno nos diga que hay sin embargo que abrir el sepulcro de Don Quijote -un texto que añade a la Vida-puesto que ahora debería ser el caballero el que nos reviviera como una luz de la estrella de la noche, etc. Y resulta curioso comprobar cómo en Unamuno, en Azorín y en Ortega, Don Quijote tiende a esfumarse. Incluso ocurre lo mismo, claro que en otro sentido, en el espléndido libro El pensamiento de Cervantes (1925) de Américo Castro.

Baste con un solo ejemplo: en sus Meditaciones Ortega considera el Quijote como "el libro-escorzo por excelencia"; pero con ello, con la metáfora lábil del escorzo, Ortega intenta remitirnos a la profundidad del pensar. Dice Ortega: “jCervantes -un paciente hidalgo que escribió un libro- se halla sentado en los elíseos prados hace tres siglos, y aguarda, repartiendo en derredor melancólicas miradas, a que le nazca un nieto capaz de entenderle!'. Lo de los elíseos prados, las melancólicas miradas y lo del 
nieto son imágenes que resultan difíciles de mejorar, desde luego. Pero como así era el estilo de Ortega, convendría dejarlas al margen para tomarnos en serio lo que dice. Pues Ortega en este ensayo nos está remitiendo a otros novelistas, a Baroja y a Azorín (para compararlos con Cervantes) y nos está remitiendo sobre todo a la falta de profundidad de la Restauración borbónica en España, con Alfonso XII y Cánovas del Castillo. El Quijote sería, en suma, un libro profundo pero sólo al sesgo, en escorzo, repite, porque lo mismo que hay un ver que es un mirar, hay un leer que es un intelligere, o leer lo de dentro, un leer pensativo”. Es verdad, para Ortega, que más que un Cristo románico, Don Quijote sería "la parodia triste de un Cristo gótico, macerado en angustias modernas" (obviamente, se trata de una concesión a la angustia de Unamuno, a quien sin embargo opone la serenidad de Fray Luis de León: Los nombres de Cristo podrían transformarse en los nombres del Quijote). Pero en realidad lo que le interesa a Ortega es mandar al garete a la España heredada de la Restauración. Esa sería una burguesía inútil e inerme. Por ejemplo: ¿Qué hubieran pensado los hombres de la Restauración del leer como intelligere, como leer lo de dentro? Muy sencillo, sentencia Ortega: pensar, es buscarle tres pies al gato. Evidentemente se necesitaba un pensamiento nuevo, pero también parece evidente que Ortega se nos presenta como si el único pensador fuera él, aun en escorzo.

Por su parte decíamos que Azorín se coloca entre Unamuno y Ortega y acompaña a Don Quijote no sólo en la ruta de 1905, sino en las Lecturas españolas de 1912, que tuvo una reedición muy poco después en la editorial Nelson, de París y Edimburgo, que es la que manejo. Luego Azorín reuniría finalmente, en la época franquista, todos sus textos cervantinos en Con Cervantes (1947: era el centenario de Cervantes) y en Con permiso de los cervantistas, ya en los años 50.

Pero ese situarse en medio de Unamuno y Ortega ¿en qué sentido nos lleva a nuestro asunto básico, es decir, al Quijote leído en clave de mujeres? Muy fácil: Azorín presenta a Don Diego Miranda, el llamado caballero del verde gabán, como símbolo fundamental del Quijote; o, mejor dicho, como su verdadera imagen en tanto que contra-símbolo definitivo. En este aspecto no valdría nada la exaltación idealista y poética de Don Quijote (como en cierto modo la borrosa figura de Lorenzo, el hijo poeta del individuo vestido de verde) frente al pragmatismo ordenado y metódico de la 
cotidianidad de la casa de Don Diego, una cotidianidad que es la que supondría el auténtico eje, la auténtica clave de la lectura del Quijote para las nuevas generaciones españolas.

2) Mas acabo de señalar la palabra realmente definitiva: la palabra casa a propósito de Don Diego. Evidentemente Don Quijote no tiene casa. E incluso del hidalgo sin nombre que nos hemos encontrado al principio y del hidalgo Alonso Quijano que nos encontramos al final, sólo conocemos dos habitaciones: la de los libros -una habitación que desaparece- y el dormitorio con la cama en la que lo hemos visto algunas veces y en la que muere. Incluso en el resto de los dos Quijotes sólo veremos otras dos casas: la de Sancho Panza y su mujer y la de Don Antonio Moreno, el rico burgués de Barcelona. Las demás aventuras que suceden "bajo techado" ocurren no en casas sino en dos ventas y dos mesones (hay una tercera venta donde no sucede nada) y en el palacio de los duques o en la residencia del gobernador Sancho en la Ínsula Barataria. El $80 \%$ de las aventuras de Don Quijote acaecen a campo abierto, al aire libre, por esos caminos del azar que es donde Don Quijote se encuentra realmente a gusto. ¡Qué diferencia con las narraciones burguesas que se difundirán tras él y en donde la casa suele ser la protagonista principal! E incluso con otro matiz: bajo techado Cervantes teatraliza siempre las acciones; mientras que al aire libre las noveliza hasta el último átomo o "anudando los hilos", como nos señalará el propio Cide Hamete.

3) Ahora bien: parece como si a Cervantes no le gustaran las casas (él mismo sólo tuvo una al final de su vida). Quiero decir: se da por supuesto que de la casa de Sancho - de la casa de unos pobres- no hace falta que se nos diga nada, pero es que tampoco de la casa del rico Don Diego se nos señalan en estricto los detalles. Apenas algunos esbozos. En verdad la descripción de esa casa se omite porque Cervantes considera tal descripción como algo que sobra, como algo consabido. Esta omisión es importante y sobre ella volveremos. Pero lo que nos importa: aparte de recordarnos el escudo de armas que hay en la puerta y de indicarnos el exterior, esto es, la bodega, la cueva del patio y las tinajas del Toboso (que eran famosas y que hacen que Don Quijote se acuerde de Dulcinea con los tristes versos de Garcilaso: "Oh dulces prentas por mi mal halladas, / dulces y alegres cuando Dios quería...”), lo que en verdad se nos resalta de la casa es el ambiente, el aire interior que allí se respira, su orden, su sosiego, su 
silencio. Y, por supuesto, la presencia/ausencia de la mujer del de Verde, Doña Cristina, a la que se supone como la creadora o regidora de ese sistema casero. Sin la presencia de esa mujer, sin su latencia a la vez doméstica y domesticadora, el orden y el sosiego de la casa no existirían. Por supuesto la división privado/público, la división entre la casa y la calle, era algo ya fijado definitivamente por las nuevas relaciones sociales. Y así como la diferencia entre pantalones y faldas (que se fija desde el XIV al XVI) distingue obviamente al vestido del hombre y al de la mujer -algo que no ocurrirá en el mundo musulmán ni en el mundo de las sotanas eclesiásticas cristianas-, no menos obvio resulta que la casa $-\mathrm{y}$ lo privado- es para la mujer, mientras que la calle y lo público son el espacio del hombre. Incluida la guerra: los pantalones serán fundamentales para la infantería de los Tercios. Puesto que esa división privado/público se solidificará aún más desde el XVIII hasta al menos los años 60 y 70 del siglo XX, cuando las cosas empezaron a cambiar (el año 1965 es el primero en el que se fabrican en Francia más pantalones de mujer que faldas: pero también, tras el 68, la presencia de la Thatcher se hará implacable, haciéndose “dueña” de la calle, de la política británica) será lógicamente, a través de esa división privado/ público, por donde deberemos investigar. Pues también lógicamente por ahí, por esa brecha entre lo privado y lo público, es por donde la imaginación de Azorín se desboca hasta el extremo, hasta convertir el orden de la casa de Doña Cristina en el supuesto y auténtico símbolo vital de lo que deberíamos leer en Cervantes frente al campo abierto y alucinatorio de Don Quijote. Y si la casa y su orden metódico se convierten con ello en protagonistas del Quijote, evidentemente Azorín tiene que convertir de igual modo en protagonista a Doña Cristina. E incluso considerándola no tanto como ángel del hogar sino, según decíamos, como la regidora o conservadora de tal orden doméstico.

4) Y no sólo Doña Cristina: puesto que las protagonistas del ensayo de Azorín serán prácticamente las mujeres en tanto que lectoras a las que se dirige el texto azoriniano. Y por eso digo que este ensayo es el único -o al menos el único que yo conozca- que está escrito leyendo casi exclusivamente el Quijote en clave de mujeres. Puesto que, aparte de Doña Cristina y su casa, el texto está dirigido casi exclusivamente a las lectoras de Azorín, a sus "queridas amigas", como se dice literalmente en el ensayo. Sólo al final aparecerá también la palabra "amigos" junto al recurrente 
"amigas", pero eso únicamente para que la moraleja del artículo resulte más global: lo que España necesita, viene a decirnos Azorín, son mentes prácticas, en vez de ilusorios Quijotes o Dulcineas. Y por eso, insisto, convierte a Doña Cristina y a su casa nada menos que en los verdaderos símbolos válidos de los dos libros cervantinos. Pero veamos lo que Azorín escribe en estricto a sus lectoras y confrontémoslo con lo que de verdad nos dice Cervantes en el capítulo XVIII del segundo libro. Escribe Cervantes:

Halló Don Quijote ser la casa [de Don Diego, al que sólo él llama "caballero del verde gabán"] ancha como de aldea; las armas, empero, aunque de piedra tosca, encima de la puerta de la calle; la bodega, en el patio; la cueva, en el portal y muchas tinajas a la redonda que, por ser del Toboso, le renovaron las memorias de su encantada y transformada Dulcinea.

Nada más. Esto es lo único que se nos describe de tal casa: una imagen difusa de su espacio exterior. Que la casa sea "ancha como de aldea" y que, sin embargo, tenga escudo de armas en la puerta (aunque por supuesto de "piedra tosca"), sólo nos indica lo que Cervantes quiere que conozcamos: que ese personaje, un poco ridículo en su vestir y en su aparente compostura, es un nuevo rico (un nuevo terrateniente o cacique se diría luego, pero no quiero ser anacrónico), algo muy distinto pues al pobre hidalgo pobre, también de aldea, que un día decidió metamorfosearse en Don Quijote. La cuestión de estos nuevos ricos de campo será algo muy serio en nuestra economía y en nuestra vida social y teatral del Siglo de Oro, tal como lo estudió, hace años, Nöel Salomon y tal como aparece en los textos de Lope y de Calderón: evidentemente la Corona quiso que incorporaran su dinero a los problemas del Estado, pero esto no lo podemos analizar ahora. Fijémonos sólo en un único detalle: tanto Don Diego como su mujer y su hijo llevan el Don delante sin ningún problema porque para eso son ricos; mientras que Don Quijote, obviamente, se ha inventado el Don, se lo ha fabricado, falsificándolo, algo que todo el mundo le reprochará puesto que ni él ni sus padres lo llevaron nunca. Incluso Sancho se asombra de que Sansón Carrasco le coloque un doña a Dulcinea, pues nunca la había oído nombrar así. Y, ciertamente, Don Quijote, tras ser armado caballero, sí que coloca un doña a las pobres rameras, la Tolosa y la Molinera, que han sido testigos del ritual de su "ser armado caballero" en la primera venta. Curiosamente, los patios de las ventas -incluso sus interiores, sus pajares, etc.- suelen ser descritos con mayor precisión que las casas, quizá porque son -para Cervantes- una 
especie de decorado de teatro, es decir, el único lugar público donde se pueden expresar las vidas interiores. Esto también es realmente sintomático y lo he explicitado mejor en mi libro. Pero volvamos con ello al patio de la casa del de Verde, que es lo que nos interesa. Lógicamente allí la mujer y el hijo de Don Diego quedan: "suspensos ante la estraña figura de don Quijote"; salvo que el texto cervantino únicamente nos añade que don Quijote se apea de Rocinante, que le besa las manos a la mujer, y que, tras decirle don Diego: "Recibid señora con vuestro sólito agrado, al señor don Quijote de la Mancha”, la señora “que Doña Cristina se llamaba, le recibió con muestras de mucho amor y mucha cortesía”. De nuevo nada más. Luego Sancho desarma a Don Quijote en una sala interior -sobre la que tampoco se nos dice nada- y nuestro caballero se lava con cinco o seis calderos de agua ("que en la cantidad de los calderos hay alguna diferencia”, añade Cervantes y esto es grandioso como minuciosidad narrativa) y Don Quijote se va con el hijo/estudiante: “en tanto que las mesas se ponían; que por la venida de tan noble huésped quería la señora doña Cristina mostrar que sabía y podía regalar a los que a su casa llegasen”. Otra vez nada más. El hijo y Don Quijote hablan de poesía y caballerías y de la diferencia entre ambas “ciencias", ya que Don Quijote pretende ir a las justas caballerescas de Zaragoza y el hijo quiere presentarse con sus poemas a unas justas literarias. Luego se van a comer con los padres, se supone, aunque de la mujer no se nos habla. Dice el texto:

(...) y la comida fue tal como don Diego había dicho en el camino que la solía dar a sus convidados: limpia, abundante y sabrosa; pero de lo que más se contentó don Quijote fue del maravilloso silencio que en toda la casa había, que semejaba un monasterio de cartujos. Levantados pues los manteles, y dadas gracias a Dios y agua a las manos...

Don Quijote pide al hijo que le enseñe los poemas que va a presentar a la justa literaria. Sólo de eso se habla y sólo se nos añade que Don Quijote pasó cuatro días "regaladísimo" en la casa y que, finalmente, decidió irse porque tenía que acudir a sus propias justas y bajar a la Cueva de Montesinos. Aunque esto le desagrade a Sancho, que se conforta rellenando sus alforjas con todas las viandas que le ofrecía la abundancia de la casa. ¿Qué nos llama la atención? Obviamente que, en todo este tiempo narrativo, en todo este capítulo interior, no aparezca ni una sola vez la mujer de Don Diego y que, por supuesto, tampoco la veamos hablar ni actuar nunca. Sólo la 
hemos oteado a la llegada; hemos leído su nombre a la hora de poner los manteles el primer día; y en este final únicamente se nos dice que: "con la buena licencia de la señora del castillo" (es la primera y única vez que Don Quijote confunde una casa con un castillo en este segundo libro) Don Quijote y Sancho se marcharon, “se partieron”.

5) En suma: la mujer de Don Diego no pinta nada en este capítulo XVIII excepto a la hora de recibir y despedir a Don Quijote y a la hora de ordenar poner los manteles y la comida ¡Y sin embargo Azorín la convierte en el símbolo básico del texto cervantino! Sin duda -suponemos- porque lo que importa es el hecho de establecer ese absoluto método de orden y ese absoluto silencio en la casa, mientras los hombres hablan de sus cosas y comen. Pues repito, ni siquiera sabemos si ella les acompaña en la mesa. Es decir, mientras los hombres hablan, todo lo demás tiene que ser silencio. Como en un monasterio de cartujos, en efecto, el respeto y el temor al Señor (o a los señores) resulta algo impecable e implacable. El silencio de la casa no es esa paz hogareña (quizás galdosiana) de la hipocresía burguesa del XIX y la primera mitad del XX, como soñaba Azorín. En absoluto. Si el silencio de la casa existe es casi aún como un signo sacralizado. Y (aunque se trate de una primera casa burguesa) el silencio es sólo un signo de que allí quien manda es Don Diego casi como Señor; y si su mujer impone ese silencio es sólo por respeto monástico/hogareño a él y a sus invitados.

Por supuesto que quizás haya también una estrategia narrativa: es posible que Cervantes utilice el silencio de este primer familiarismo burgués, el silencio de la casa del nuevo rico de Verde, acaso para contrastarlo con el capítulo siguiente, para contrastarlo con el alborozo y las fiestas de la casa y los jardines de otro nuevo rico, el episodio de las Bodas de Camacho. Pero en ambos casos sólo para resaltar el valor del dinero, pues la riqueza ostentosa del vestido verde en el primer caso y la algarabía ostentosa de las bodas fallidas de Camacho, sólo sirven para que Sancho suelte su famoso apotegma: que ya no hay linajes en el mundo y que lo único que cuenta es el tener y el no tener. Y esto sí que es una primera ideología capitalista hasta el extremo.

6) Y sin embargo Azorín no tiene en cuenta el texto cervantino para nada en absoluto. Sólo le importan Doña Cristina y su casa; y ese orden silencioso impuesto por ella y que a Azorín le parece de perlas. Con un solo problema: como la protagonista de Azorín prácticamente no existe y la casa tampoco existe (pues Cervantes se limitaba a 
decirnos que era la casa típica de un hidalgo rico de aldea, algo que cualquiera podría imaginar y que describirla supondría una digresión que se apartaría de la eficacia narrativa de la verdad: por cierto que Agatha Christie dice lo mismo en El secreto de Chimneys, publicado en 1927 y con no menos sarcasmo), Azorín, digo, se tiene que inventar inevitablemente a la protagonista y a $s u$ casa. Esas protagonistas que no existen en Cervantes salvo quizás, como sugeríamos, en tanto que ausencias/presencias latentes. Pues fijémonos en lo que dice Azorín. Exactamente esto:

Doña Cristina se encuentra en esa edad en que las mujeres hacen soñar a los muchachos que están en los colegios; tal vez tiene una barbilla que se repliega suavemente sobre el angosto cuello del corpiño; acaso en sus ojos hay esa vaga melancolía, esa dulzura, esa añoranza que tenéis vosotras, buenas amigas, cuando estáis a punto del despediros de la edad loca...

No pido que nadie se ría o que llore ante este "invento", sino sólo que me siga acompañando en el trayecto de su protagonista, la cual, siempre según Azorín, recibe en efecto a Don Quijote. ¿Pero de qué manera lo recibe? Azorín lo describe así: "Doña Cristina dobla la cabeza y sonríe con una de esas ligeras sonrisas que vosotras, buenas amigas, tenéis, y que nos confunden un poco, puesto que no sabemos si son de ingenuidad o de ironía...” Pero claro está que una vez que Azorín se ha inventado a la protagonista (en complicidad con sus amigas lectoras, las aún jóvenes señoras casadas que leían la revista La Lectura), Azorín se ve igualmente obligado a inventarse la casa, como decíamos. Primero la Sala en la que Sancho desarma a Don Quijote: allí hay (o habría) armarios con libros, magníficos cuadros, cornucopias, anchos sillones con respaldar entapizado; incluso Azorín se inventa a una criada que mira. Salvo que esta primera descripción le debe parecer demasiado objetiva: ahí lo único que se resalta en el fondo es la riqueza del dueño. Por tanto, y para que la mujer sea la verdadera protagonista, Azorín tiene que inventarse también el mundo interno de la casa, el orden impuesto por la mano y la dirección de ella. Y así nos dice:

(...) en la casa se respira un ambiente de sosiego, de paz; los muebles están colocados simétricamente; todas las cosas diarias se hacen a la misma hora; las comidas están siempre a punto cuando llega el mediodía y cuando llega la noche; a idénticos instantes se abren por la mañana las puertas y ventanas y se toca a retirada por la noche... 
No sé muy bien lo que significa la identidad de los instantes o ese toque de retirada que suena a cuartel o a monasterio, en efecto. Pero eso no importa. Lo que importa es resaltar el orden perfecto de nuestra protagonista inventada, y no digamos por lo que acaece en los detalles concretamente familiares. Pues aquí Azorín se esmera: “se guardan y conmemoran todas las fiestas y sucesos de la familia; los manteles no están nunca manchados ni se verá jamás un desgarrón en los atavíos de las camas; la ropa blanca está guardada...”. Por supuesto a esa ropa blanca la acogen cestos aromados con membrillos y siempre preparados para el invierno o el verano. No quiero comparar estas normas caseras de Azorín con las Normas de urbanidad para señoritas de Pierre Loüys, casi de la misma época. Aunque efectivamente sean también normas para casadas o casaderas. Pero es que Azorín va más allá: bajo esta mujer protagonista, la auténtica protagonista es España y el orden que "Ella" pretende establecer -o el orden que debe establecerse sobre Ella-. Esto es, el método y el orden -son palabras de Azorín- que nuestra protagonista ha impuesto. Y de ahí la paz y el silencio de la casa. Azorín (primum anarquista pero conservador casi desde siempre y franquista siempre) no podía imaginar, en 1912, que luego vendrían 25 años de paz y 40 años de Tiempo de silencio. Pero, desde luego, las hijas o las nietas de sus lectoras sí que iban a coadyuvar hasta el fondo con esos tiempos de paz y de silencio. Y, por supuesto, que las lectoras burguesas o pequeñoburguesas de Azorín lo que sí sabían era verse en ese texto con todos sus ideales cotidianos reflejados como en un espejo sublimador ¡Y además todo eso lo habría dicho el gran Cervantes! Claro es que no se trataba de Cervantes, sino que todo eso se lo había inventado Azorín. Pero es precisamente en este sentido en el que decíamos que su texto resulta fascinante. Por su parte, Cervantes sólo nos había mostrado que una mujer, por muy rica que fuera, era siempre sierva de su marido; que cuando los hombres estaban presentes ella debía ser invisible, ocuparse sólo de la comida y los manteles y nada más. El resto es algo que ha surgido del inconsciente pequeñoburgués de Azorín. Y por eso Azorín concluye con una pregunta definitiva, la que da sentido a la moraleja de esta pequeña historia (igual que "pequeño filósofo" se llamó el propio Azorín). Y la cuestión es obvia: si el orden y el método de la casa de Don Diego suponen el auténtico contraste con la falta de orden y método de las alucinaciones de Don Quijote, habrá que establecer el sentido práctico en la vida española. Lo cual no deja de resultar sarcástico, visto desde hoy: lo que Cervantes nos 
dice en el capítulo XVI es que Don Diego había enviado a su hijo a Salamanca para que, tras pasarse seis años estudiando las lenguas clásicas, la griega y la latina, se dedicase luego a estudiar las "ciencias serias", es decir, estudiar leyes (que, por supuesto, implicaban una jurisprudencia basada en el Derecho Natural sacralizado) y en especial "la reina de todas la ciencias", es decir, la Teología. Pero que su hijo se "había embebido en la poesía, si es que se puede llamar ciencia”. La respuesta de Don Quijote es básica al menos en tres sentidos que quisiera esquematizar: primero la imagen de la poesía como ornatus, al comparar Don Quijote a la poesía con la "mitra" de los obispos o la "garnacha" (la toga) de los "peritos juriconsultos", o sea, de los abogados; en segundo lugar, la imagen de que la poesía no debe ser publicada ni tirada por las calles (pues es una doncella pura) para que la manosee el vulgo; aclarando que "vulgo" debe considerarse todo aquel que no "sabe", no sólo la gente humilde sino cualquier señor o príncipe; y en tercer lugar, que el hijo no debería dedicarse sólo a los clásicos y despreciar la lengua romance o vulgar, la "natural de cada uno". Pues Homero no escribió en latín (porque era griego) ni Virgilio escribió en griego (porque era latino). Cualquiera puede en fin escribir en su "lengua natural", incluso -y aquí viene lo más ambiguamente doloroso- aunque sea en la "vizcaína". Yo, con todo, no me atrevería a asegurar rotundamente que no se filtre ahí (pese al lastimoso tópico de la época) un oblicuo respeto precisamente contra el tópico; al igual que Cervantes había defendido la gallardía y el valor del criado/ hidalgo vizcaíno con el que se enfrenta Don Quijote y que pierde en el duelo porque su mula "de alquiler" es peor aún que Rocinante. La defensa de la lengua vulgar o natural (el erasmismo de Vives o Valdés; las posturas de Dante o Petrarca, de Du Bellay o Sydney, la Biblia de Lutero) no incluye sólo pues al alemán o al castellano sino también al vizcaíno: y esa presencia en absoluto es despreciativa aquí, a pesar del "aún" que se introduce antes (“aún al vizcaíno que escribe en la suya"), sino que tal mera presencia implica ya un respeto, un reconocimiento de que tal lengua existe (también ocurre en el combate: se nos dice que el criado/ hidalgo habló "en mal castellano y peor vizcaíno")

7) Pero vayamos a lo que ahora nos interesa: Cervantes hace una defensa de la poesía como "ciencia" (lo que había negado el de Verde), e incluso de la poesía en "vulgar" o en "romance" porque los clásicos (griegos o latinos) sólo son ejemplo del 
arte. Puesto que el poeta "nace", es "naturaleza" (otra imagen de lo natural, que también recoge Lope obviamente) debe, sin embargo, pulir ese natural con el conocimiento de los clásicos y de las otras lenguas poéticas. Pues así “imagino (añade Don Quijote, y esto es magnífico) que vuestro hijo debe estar mal no con la poesía de romance sino con los poetas que son meros romancistas", es decir, los que no se ayudan del arte ni antiguo ni moderno. E incluso hablando luego con el hijo del de Verde, el estudiante/ poeta don Lorenzo, Don Quijote le dirá que en los premios (o justas) literarios ocurre como en la Universidad: que es mejor ser "segundo" porque el primero siempre está dado por la "calidad" (nobiliaria o eclesiástica) de la persona, no por la calidad de los versos, etc. Aunque evidentemente Don Quijote comprende que el hijo del de Verde se considere el mejor poeta del mundo puesto que no hay poeta que no se considere así. Y esto es lo que sucede en el "silencio maravilloso" de la casa de don Diego.

En una palabra: mientras los hombres comen y hablan, la mujer, doña Cristina, debe imponer ese respetuoso silencio en toda la casa. El silencio ideal para que los hombres trabajen, repito: las mujeres son guardianas de la casa como los dominicos se consideraban domini-canes, perros guardianes de la casa del Señor. Pero, curiosamente, las mujeres en tanto que guardianas de la privatización carecen, sin embargo, de privatización propia, son propiedad privada de las formas familiares del sistema: el padre, los hermanos, el marido, etc. Y Freud lo planteaba brutalmente. Más o menos así: 1) A la mujer sólo se le permite pensar en la privatización; 2) pero la clave de la privatización es el sexo, y a la mujer se le prohíbe pensar en el sexo; 3) en consecuencia: las mujeres no piensan. Claro que en su madurez final Freud se vio atascado ante su terrible pregunta: ¿Qué desea la mujer? Más que plausiblemente Azorín estaría opacamente de acuerdo con el aserto de que las mujeres no piensan, pero en absoluto se le hubiera ocurrido inquietarse por el hecho de que la mujer es y desea (algo de lo que hablaremos enseguida). Sólo le interesa la familiaridad, por supuesto.

Por otra parte, Azorín se equivoca en este capítulo XVIII, puesto que sigue llamando a Don Quijote “Caballero de la Triste Figura”, cuando en verdad -a partir del capítulo XVII y en presencia del propio don Diego Miranda- se ha convertido ya en el "Caballero de los Leones". Pero lo importante es la manera en que Azorín esquiva la 
cuestión de la poesía diciendo que don Diego no ha conseguido que su hijo se dedique a "más provechosas y sólidas especulaciones". Mientras que lo que Cervantes escribe es, como hemos visto, que aparte de estudiar leyes, el hijo debería haber estudiado Teología (evidentemente una especulación "sólida y práctica"). Y digo que Azorín esquiva esto, puesto que lo que Azorín señala no es lo de la Teología, sino que el hijo debería llegar a ser un "excelente agricultor o un laborioso mercader", algo que ocurrirá "acaso con el tiempo, desencantado de sus quimeras y de sus sueños".

8) Azorín nos está dando, pues, una lección de practicismo moral, ese sentido práctico que sería necesario implantar en la vida española. No sólo entre las mujeres que ya lo tienen y por eso son protagonistas azorinianas- sino también en los hombres. Por ello Azorín introduce ahora también el sintagma masculino "buenos amigos". Dice: "Y yo os pregunto, amigas mías, buenos amigos, ¿qué creéis que importa más para el aumento y grandeza de las naciones?”. Y el contraste de Azorín no puede ser más absurdo a la vez que inevitable: la dicotomía se establece entre los espíritus solitarios y fantásticos -como Don Quijote- o, por el contrario, "estos otros prosaicos, metódicos”... como Doña Cristina y Don Diego. No es poco, sin embargo, lo que nos plantea Azorín: pasar de la casa de Doña Cristina (como símbolo del Quijote) nada menos que a La riqueza de las naciones de Adam Smith. Salvo que Azorín es taxativo: habrá que respetar a los solitarios y alucinantes, a los "poéticos", pero prefiramos sobre todo a los segundos. Y aquí la invención máxima de Azorín, que sin embargo se sitúa, en efecto, entre Unamuno y Ortega: ese preferir a los prácticos habría sido el mensaje perdurable de Cervantes. Y con ello nosotros, finaliza Azorín, en vez de locuras alucinatorias, deberíamos desear: "tener una pequeña renta, una tiendecilla o unos majuelos”.

No se trata pues de la mística laica de Unamuno ni de la razón vital de Ortega (ni siquiera del escuela y despensa de Joaquín Costa). Se trata, en efecto de una mentalidad de pequeño tendero o pequeño rentista que amparará de hecho el levantamiento de Franco en 1936. Es por eso por lo que hablo del inconsciente pequeñoburgués de Azorín: no sólo por la tiendecilla o por la pequeña renta, sino, sobre todo (aunque por supuesto Azorín tenga derecho a reescribir el Quijote como quiera) por la aparición última de esos "majuelos", que fuerzan al sarcasmo de las lectoras o los 
lectores de hoy: tener unos majuelos significaría que Don Diego Miranda tendría apenas unas pocas viñas, mientras que, evidentemente, las viñas manchegas de un nuevo rico, un nuevo hidalgo ostentoso como el del Verde Gabán, debían ser inmensas. Lo de la tiendecilla, la pequeña renta y los majuelos es algo que tiene tan poco que ver con el Quijote como la invención de Doña Cristina y su casa. Una cosa es reescribir el Quijote y otra cosa es leerlo mal. Evidentemente Don Diego no sólo es un gran rico sino que se muestra como tal (ostentosamente, repito) al vestir de verde desde el gorro hasta las espuelas. Era posiblemente una manera de imitar a la auténtica nobleza, pues luego veremos a la duquesa a caballo, con un azor en la mano, pero también vestida de verde de los pies a la cabeza. De modo que lo malo de esta lectura del Quijote (la que Azorín hace en clave de mujeres) podemos decir que es su carácter de novelita ejemplar. El ejemplo que se nos ofrece -la mujer y la casa indisociables- con Doña Cristina como protagonista, como dueña de su hogar y sierva de su marido y regidora del silencio. Sin duda es un modelo que a Azorín le parece absolutamente válido a la altura de 1912. Y que cada uno o cada una piense lo que quiera a propósito de los manteles blancos y las camas impolutas. Lo asombroso, sin embargo, es que en el revolucionario año 1968, el texto de Azorín se siguiera considerando como uno de los mejores ejemplos -nunca mejor dicho- del ensayismo moral escrito en español, tanto en España como en Hispanoamérica. Y que así se nos ofrezca, por ejemplo, en el libro titulado Siglo $X X$, editado por los profesores Luis Leal y Joseph H. Silverman, gracias a la ayuda conjunta de las universidades de Illinois y de Los Angeles. Y es una imagen que se sigue mostrando en la mayoría de la bibliografía considerada como válida actualmente. El ejemplo de la novelita o el ensayo de Azorín sí que parece presentársenos como perdurable. Nada extraño por otra parte: sólo una prueba más de que la problemática teórica de fondo -desde 1905- no ha variado en exceso, como indicábamos al principio: Don Quijote sería el ideal o lo trascendental y Sancho lo empírico o mundano. Algo que se venía arrastrando desde los neokantianos y los románticos (y los empiristas anglosajones posteriores). Y algo que se incrustaba como las dos mitades del alma humana. Como decíamos, a Borges (en 1947) esta hipótesis ya le parecía monstruosa. Pero esos lugares comunes han permanecido prácticamente hasta hoy. En sus Lecturas españolas Azorín lo único que hace es trasladar ese desdoblamiento (lo ideal vs. lo concreto/ empírico) nada menos que a toda la visión moral de España enlazándola con 
el símbolo de una mujer, la Doña Cristina inventada. ¡Qué imagen más práctica que la cotidianidad de una mujer hogareña!

9) Y resulta sintomático: en este sentido Azorín se sabía perfectamente quiénes debían ser obviamente las protagonistas auténticas del Quijote: Doña Cristina y su casa. Y no sólo frente a Marcela o Dorotea sino frente al Quijote mismo. Ahora bien: resulta claro que este saber de Azorín como lector del Quijote es un saber excesivo. No sólo resulta intolerable hoy sino que también es falseador respecto al texto de Cervantes. El solitario Cervantes y el solitario Don Quijote nunca supieron quiénes eran realmente. Y mucho menos las mujeres del Quijote: ni siquiera la mujer de Sancho que se rindecomo el propio Sancho- ante el sadismo cretino de la carta de la duquesa, que por lo demás está arruinada y es una asesina. Ni siquiera nosotros sabíamos que Rocinante era un caballo sin castrar, un caballo "entero" -esto es, de guerra y no de labranza- hasta que se aproxima a las yeguas, con "un trotico algo picadillo", para comunicar "su necesidad con las señoras jacas". Es una equivocación, porque las yeguas tienen más ganas de pacer que de lo otro, pero eso, recordamos, le sirve a Cervantes para enlazar la historia con otra equivocación genial: la de Don Quijote y Maritornes palpándose en el camastro y luego la de la propia Maritornes ayudando al manteado Sancho incluso con un vino que ella misma paga. La presencia/ausencia carnal de Dulcinea (y en absoluto la de Doña Cristina) sí que será el hilo rojo, la clave del segundo libro; pero la perversidad erótica de Altisidora resulta magnífica en la aventura gatuna del palacio. Cuando le susurra al caballero maltrecho y en la cama que ojalá no se desencante nunca Dulcinea para que no pueda gozar de ella. Es curioso cómo en el sigloXVII las mujeres hablan siempre de goce (mientras que se achaca a los hombres la imagen de la burla, del engaño erótico respecto a las mujeres), pero ese reconocimiento del deseo de la mujer se convertirá en evanescente a partir de la burguesía del XIX. Claro que la libido femenina -como la masculina- no siempre es erótica: la mujer del ventero sólo desea que se lean libros de caballerías porque así su marido la deja en paz en sus tareas domésticas; mientras que, por el contrario, su hija y Maritornes sí desean oír esos libros porque allí hay "cosas de mieles". Que luego Cervantes las llame a ambas "semidoncellas" cuando atan el brazo de Don Quijote al cerrojo del pajar y lo someten -quizás sin quererlo- al tormento de la garrucha, es también algo magnífico: ¿qué significa semidoncellas?, 
¿saben ellas lo que son?, ¿pueden decir yo sé quién soy?, ¿lo sabe -o lo puede decirAna Félix, la cristiana/morisca que tiene que vestir a su novio de mujer para salvarlo de las costumbres turcas de Argel (los turcos preferían a los jovencitos) y que no sabe cuál será su destino tras su liberación en Barcelona?

Y fijémonos: si Don Quijote se considera caballero en aprobación en el primer libro y luego caballero auténtico -porque ya está en escrito- en el segundo libro, sin embargo sólo se considerará caballero de verdad en el palacio de los Duques, es decir, en medio de una farsa cruel. Aunque don Quijote nunca se dé por vencido, nunca se rinda por sí mismo, salvo ante las dos jovencitas juguetonas que le hacen bailar demasiado en la fiesta de la casa de Don Antonio Moreno también en Barcelona. Pero estas dos chicas son sólo un esbozo, un arquetipo urbano frente a la realidad rural de Sanchica y frente al ama o la sobrina que únicamente cobran vida al ayudar a quemar los libros o al recibir la herencia que les deja nuestro protagonista al morir.

10) En una palabra: en el Quijote nadie puede decir yo sé quién soy. Y mucho menos las mujeres que son tan invisibles (globalmente) en el XVII como lo son hoy (los casos particulares y los planteamientos sobre la igualdad o la diferencia no podemos tratarlos aquí). Y como final: el desconcierto llena tanto las vidas de este libro que quizá sólo podríamos considerar como cierta la frase del Quijote tras el desastre de la barca del Ebro: "todo este mundo es máquinas y trazas contrarias unas de otras. Yo no puedo más”. O acaso la rebelión de Sancho, al irse por su cuenta del gobierno de la Ínsula y espetar a los siervos de los duques su frase más decisiva: "O somos o no somos". Una forma indudable de afirmación pero, a la vez, otra forma sinuosa de decir yo (no) sé quién soy. Pero Sancho al menos sabe que lo único que vale es el tener o el no tener, y por eso consuela a su mujer en el regreso: "Dineros traigo, que es lo que importa”.

Eso era acaso lo único que sí sabía el propio Cervantes, que por ello se muere sabiendo que está "muy enfermo y muy sin dineros". Y el resto es sólo el gran "cuento chino" que el propio Cervantes se inventa quizás para recordarnos (y, por supuesto, no sólo al conde de Lemos), que el Quijote en absoluto ha sido nunca un cuento chino y que no hay que decir fruslerías sobre ese libro cuando se lee en clave de mujeres (como Azorín) o en cualquier otra clave. Pues se trata nada menos, en el Quijote, de la posibilidad -o no- de elegir libremente la propia vida. Algo que nosotros o nosotras 
quizá nunca lograremos. Aunque tal desafío concreto sea el verdaderamente fundamental incluso cuando tengamos que decir: yo no puedo más.

11) Claro que si de aventuras eróticas hablamos $-\mathrm{o}$ al menos de la relación de Don Quijote con sus deseos y sus mujeres- yo me quedaría con las dos escenas en que Don Quijote tiene miedo de poder o no poder. Así en el aludido palparse equivocado de Don Quijote y Maritornes en el capítulo XVI del primer libro, cuando nuestro caballero confiesa "con voz amorosa y baja" que -además de por su amor a Dulcinea- él no podría satisfacerla a ella pues, tras la paliza que le han dado los yangüeses/ gallegos, se halla absolutamente "molido y quebrantado". Esta literalidad del no-poder sí que me fascina; al igual que en el capítulo XLVIII del segundo libro, Don Quijote teme nopoder sujetar sus deseos por culpa de las dueñas -y del diablo-; ya que al necesitar ver carnalmente a Dulcinea (al necesitar que Dulcinea sea verdad) cualquier mujer podría despertarlo. Y así volvemos otra vez al silencio, pero en este caso a la soledad y el silencio de su propio dormitorio en el Palacio de los Duques. Dice Don Quijote dudando: "Y ¿quién sabe si esta soledad, esta ocasión y este silencio despertará mis deseos que duermen...?" (Incluso Cide Hamete se ríe, "por Mahoma", ante la posibilidad, anotábamos, de ver a Don Quijote y a doña Rodríguez cogidos de la mano en la habitación a solas y yéndose al lecho).

De modo que Don Quijote sabe que sí tiene deseos, quizás los que le ha despertado la activa Altisidora dos capítulos antes, en la también aludida aventura gatuna, al susurrarle, decíamos también, que todo aquello le había sucedido por no haber querido acostarse con ella y haber preferido a Dulcinea. Esto se lo recuerda Altisidora (como luego en su despecho diabólico, en su desprecio hacia Don Quijote tras la falsa muerte de ella) ¿sólo en sentido de burlas o es que ha sido bien real el fracaso del deseo de Altisidora de despertar los deseos que duermen, pero que se perciben, en Don Quijote, lo que Freud señalaba como el terrible despecho de la mujer?

Imagino que hay un poco de todo. Puesto que sabemos de sobra que la dueñas, en el XVII, eran consideradas diabólicas en efecto, y no podemos olvidarnos nunca del magnífico ménage a trois que hacen, durante casi una noche, la dueña Placer de mi vida, Tirante y la princesa en el capítulo CXV del Tirant lo Blanc... 
Quizás a eso lo hubiera llamado Maritornes "cosas de mieles". Salvo que en el Tirant no hay miedo y en el Quijote sí, pues ya no es un libro de caballerías. En el Quijote hay miedo incluso al deseo y por eso se intenta "encubrir lo demasiado humano". Al contrario de lo que sucede en el Tirant o en la admirable -y admiradaCelestina ("Libro a mi entender divi-/ si encubriera más lo huma-", lo llamará Cervantes). Claro que en su época Martorell o Rojas podían escribir sin problemas las “cosas de mieles". Y eso era ya imposible en el 1605-1615 de Cervantes.

Pero lo que nos llama la atención (en este ejercicio de le lectura) es el síntoma clave de todo. O sea, que en el siglo XX a Azorín sólo le iba a importar inventarse la casa, la mujer y los cestos de ropa aromados con membrillos: el orden del silencio de la mujer en la historia. A veces hay lecturas "edificantes" y que convendría no olvidar.

(Artículo recibido: 17-06-2010; aceptado: 26-06-2010) 